\title{
Characterizing Levels of Reasoning in Graph Theory
}

\author{
Antonio González ${ }^{1 *}$, Inés Gallego-Sánchez ${ }^{1}$, José María Gavilán-Izquierdo ${ }^{1}$, María Luz Puertas ${ }^{2}$ \\ ${ }^{1}$ Department of Didactics of Mathematics, Universidad de Sevilla, SPAIN \\ 2 Department of Mathematics, Universidad de Almería, SPAIN
}

Received 5 February $2021 \cdot$ Accepted 8 April 2021

\begin{abstract}
This work provides a characterization of the learning of graph theory through the lens of the van Hiele model. For this purpose, we perform a theoretical analysis structured through the processes of reasoning that students activate when solving graph theory problems: recognition, use and formulation of definitions, classification, and proof. We thus obtain four levels of reasoning: an initial level of visual character in which students perceive graphs as a whole; a second level, analytical in nature in which students distinguish parts and properties of graphs; a pre-formal level in which students can interrelate properties; and a formal level in which graphs are handled as abstract mathematical objects. Our results, which are supported by a review of the literature on the teaching and learning of graph theory, might be very helpful to design efficient data collection instruments for empirical studies aiming to analyze students' thinking in this field of mathematics.
\end{abstract}

Keywords: levels of reasoning, van Hiele model, processes of reasoning, graph theory

\section{INTRODUCTION}

The community of researchers in mathematics education has paid special attention to the teaching and learning of discrete mathematics, as shown by the recent creation of a specialized group on this subject at the 13th International Congress on Mathematical Education (Hart \& Sandefur, 2018). Discrete mathematics deals with the study of structures based on discrete sets (finite or numerable sets), such as integers, graphs, or codes (Biggs, 2003), which are fundamental in developing disciplines such as computer science, operations research, or combinatorial optimization (e.g., see Beineke \& Wilson, 1997). In particular, graphs play a significant role in the mathematical training of undergraduate students in engineering, economics, and of course, in mathematics (González, Muñoz-Escolano, \& Oller-Marcén, 2019; Kolman, Zach, \& Holoubek, 2013; Milková, 2009; Vidermanová \& Melušová, 2011). This is due to their usefulness as tools for modeling real-life problems, which gives them high applicability in different areas such as transportation networks, telecommunications, social networks, scheduling tasks, or big data (Derrible \& Kennedy, 2011; Hart, 2008).

Students' knowledge of graph theory has been proven as a powerful tool for understanding other disciplines: chemistry (Bruckler \& Stilinović, 2008), physics (Toscano, Stella, \& Milotti, 2015), or computer science (Kasyanov, 2001). However, few studies have researched students' reasoning about graph theory, as noted by Hazzan and Hadar (2005), and Medová, Páleníková, Rybanský, and Naštická (2019), although numerous works in multiple fields of mathematics point out the importance of studying students' reasoning to design effective tasks sequences or explain the success or failure of different teaching strategies (Brito, Almeida, \& Osório, 2020; Chaphalkar \& Wu, 2020; Hokor, 2020; Yao \& Elia, 2021). These facts demonstrate the need to develop theoretical frameworks that support this type of research. In response to this need, we proposed the van Hiele model as a candidate to characterize the learning of graph theory (Gavilán-Izquierdo \& González, 2016), which was also suggested by Ferrarello and Mammana (2018).

The van Hiele model provides a description of the degree of complexity in students' reasoning concerning a certain mathematical concept (Jaime \& Gutiérrez, 1990). In the geometric case, which has been the most studied in literature (Aires, Campos, \& Poças, 2015; Armah \& Kissi, 2019; Bleeker, Stols, \& Van Putten, 2013; Burger \& Shaughnessy, 1986; Gutiérrez, 1992; Jaime, 1993; Mayberry, 1983; Pegg, Gutiérrez, \& Huerta, 1998;

(c) 2021 by the authors; licensee Modestum. This article is an open access article distributed under the terms and conditions of the Creative Commons Attribution License (http://creativecommons.org/licenses/by/4.0/).

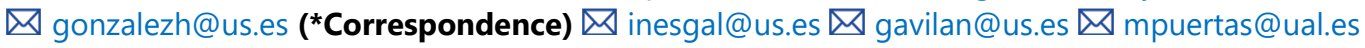




\section{Contribution to the literature}

- This paper is one of the few studies that have researched the learning of graph theory, thus providing a characterization of different levels of understanding in this field of mathematics.

- The study contributes to the literature on the van Hiele model by providing an extension to the learning of graph theory.

- We have developed a methodology with the aid of the processes of reasoning (recognition, use and formulation of definitions, classification, and proof), which have only been applied in the particular case of geometry so far.

Usiskin, 1982; Van Hiele, 1986), there exist five levels of understanding:

- Level 1 (recognition). Geometric figures are perceived in a purely visual way and as a whole, without differentiating their parts or properties. In addition, they are described in terms of physical attributes or comparisons with everyday objects, thus showing a lack of mathematical language at this level.

- Level 2 (analysis). This level is determined by the recognition of the parts of the figures and their properties (although not the relationships between them), which allows a description of the figures in mathematical terms.

- Level 3 (order). Relationships between the mathematical properties of the figures can be recognized at this level, which reveals a certain handling of propositional logic that, although it allows students to make logical classifications of families of figures, it is still insufficient to write formal proofs.

- Level 4 (deduction). This level is characterized by the ability to write formal proofs of mathematical statements and the handling of equivalent definitions for the same concept. However, the reasoning at this level is restricted to Euclidean geometry.

- Level 5 (rigor). This is the maximum degree of geometrical reasoning, which allows to establish and analyze results in different postulation systems, thus extending the theorems learnt in the preceding level to non-Euclidean geometries.

(Note that this is only a general description of the van Hiele levels in geometry. Gutiérrez and Jaime (1998) provide for the four first levels a more accurate characterization based on the degree of skill that must be achieved at each level for each of the so-called processes of geometric reasoning: recognition, use and formulation of definitions, classification, and proof).

Hence, applying the van Hiele model to graph theory is natural if we take into account the similarities between graphs and geometric figures (Alsina, 2011). Indeed, graphs are usually represented as points on the plane joined by lines, thus reminding us of the vertices and sides of geometric figures. Also, dealing with both mathematical objects requires handling the transformations that leave them invariant. In the geometric case, only rigid movements (translations, rotations, and symmetries) leave geometric figures invariant, which are particular cases of the transformations that leave graphs invariant, this is, the so-called topological transformations (Vergel, Molina, \& Echeverry, 2005). In fact, children develop topological intuitions before geometric relations (Piaget \& Inhelder, 1956), which require paying attention to different aspects such as angles or lengths. Hence, it looks reasonable to extend the van Hiele model to graphs as they can be regarded as a generalization of geometric figures with more manageable features. Furthermore, this model has been developed in fields that are further from geometry than graph theory: local approximation (Llorens-Fuster \& Pérez-Carreras, 1997), convergence of sequences (Navarro \& Pérez-Carreras, 2006), functions (Nisawa, 2018), etc.

Our aim in this paper is to characterize the student's understanding of graph theory using the van Hiele model as theoretical framework. In order to achieve this, we extend the specific characterization for the particular case of the recognition process (González \& GavilánIzquierdo, 2017) to the remaining processes involved in the learning of graph theory. For each of these processes, we provide a series of descriptors according to their development through the four levels of reasoning that we propose here. We have skipped the description of a fifth level since it is not characteristic of students but of professional mathematicians (Díaz-Levicoy, 2010; Hoffer, 1988), and so it exceeds the scope of this work.

\section{LITERATURE REVIEW}

Regarding the learning of graph theory, among the few studies that look into the reasoning of students, we highlight the work by Hazzan and Hadar (2005), who analyze the understanding of university students from the perspective of the reduction of the level of abstraction. Indeed, these authors observe students' unconscious mechanisms of reducing abstraction derived from an excessive emphasis on visualization. Another remarkable work of this kind is thanks to Medová et al. (2019), who categorize and analyze the errors made by university students when dealing with classical graph algorithms. 
In contrast, there is a wealth of literature on the teaching of graph theory. In particular, many research papers on this topic are devoted to the design of task sequences on graphs for basic education (primary and secondary education), such as those of Cartier (2008), Gibson (2012), Hart and Martin (2018), Smithers (2005), and Wasserman (2017). This type of work usually reflects the need to use a non-formal language when defining graph concepts in basic education. For instance, these concepts are commonly introduced through popular games, such as dominoes (Oller-Marcén \& Muñoz-Escolano, 2006), or real-life problems that can be easily modeled, such as map coloring or incompatibility situations (Schindler \& Joklitschke, 2015). Moreover, these works pay special attention to the role of visualization because of its fundamental support in the beginning of the teaching of graph theory, as we can check in older and recent papers. Indeed, Niman (1975) points out that visual tasks ease learning, and Schindler and Joklitschke (2015) mention that students, when solving problems, are less capable of seeing the underlying mathematical structure in the absence of direct visualization. Likewise, Ferrarello and Mammana (2018), inspired by the van Hiele model, present a sequence of activities organized by levels, thus starting with visualization and description activities until reaching those that require more reasoning and logic. More generally, the usual pattern of these works is to start with concrete examples that students can visualize, to later increase the level of abstraction and formality in the concepts that are being studied. For example, it is common to find teaching sequences for the concept of Eulerian graph that begin with specific examples and then continue by enhancing the progressive deduction of the necessary and sufficient conditions that characterize this family (Menéndez, 1998; Oller-Marcén \& MuñozEscolano, 2006; Santoso, 2018; Vergel et al., 2005).

Other works address the teaching of graph theory at university level (Chinn, 1993; Milková, 2009; Tabchi, 2018; Tabchi, Sabra, \& Ouvrier-Buffet, 2019), which generally involves tasks with greater complexity than in basic education. However, Milková (2009) highlights the importance of visualization in the teaching of graph theory also at tertiary level (even if students must achieve a formal understanding of this subject), pointing out its relevance to assimilate graph concepts and handle algorithms. These studies emphasize practical applications of graphs as tools to model real situations, for instance, in problems of finding optimal transport routes. On a more theoretical level, Tabchi et al. (2019) notice the need to connect graph concepts in engineering courses. Finally, the work by Chinn (1993) focuses on the discovery method and outlines many advantages in its use, supporting these findings with empirical research.

Besides the studies mentioned above, there exists another type of work describing teaching resources, such as the use of puzzles (Milková, 2014) or computer tools that help students deal with graph activities, especially visualization and execution of algorithms (Costa, D'Ambrosio, \& Martello, 2014; Do, Nguyen, \& Mai, 2018; Geschke, Kortenkamp, Lutz-Westphal, \& Materlik, 2005). Also, there are papers devoted to reflection on the teaching of graph theory, thereby giving support to its inclusion in different educational programs (Hart, Kenney, DeBellis, \& Rosenstein, 2008; Rosenstein, 2018).

\section{Fundamentals of Graph Theory}

We now provide the basic notions of graph theory (Biggs, 2003) that we need in order to present our learning model.

A graph is a set of elements that are interrelated by a binary relation. More formally, a graph $G$ is defined as a pair $(V, E)$ where $V$ is any given set (called vertex set), and $E$ (edge set) is a set of unordered pairs of elements of $V$. Graphs can be represented in several ways, but the most common is known as pictorial representation, which consists of representing vertices as points and joining vertices with a (non-necessarily straight) segment whenever the corresponding pair of vertices is an edge. For instance, a pictorial representation of graph $G_{1}=(\{a$, $b, c, d\},\{a b, b c, c d, a c, a d\})$ is depicted in Figure 1(a). There exist other representation systems whose use may be advantageous depending on the problem to be solved. Indeed, graphs can be represented by a symmetric matrix whose rows and columns correspond to the vertices of the graph, and entries equal to 1 for vertices connected by an edge and 0 otherwise (see Figure 1(b)). We can also represent graphs as an intersection of objects, thus drawing vertices as flat geometric objects and assuming that edges are given by pairs of objects that intersect (see Figure 1(c)). Finally, graphs can be represented as sequences of degrees, given by numerical sequences whose elements indicate, for each vertex, the number of edges incident to it (see Figure 1(d)). In this work, we mainly focus on pictorial representations since they are the most used in the literature about graphs.

The pictorial representation of graph $G_{1}$ given in Figure 1(a) is not unique, as we can see in Figures 2(a) and 2(b). Thus, any continuous deformation applied to a specific representation of graph $G_{1}$ will give rise to another representation of $G_{1}$ whenever the original connections between vertices are preserved. Furthermore, we can observe that graph $G_{2}=(\{x, y, z, t\}$, $\{x y, y z, z t, x z, x t\})$, depicted in Figure 2(c), provides the same combinatorial information as $G_{1}$ : it is a set of four elements in which two of them are related to each other and the remaining two vertices. Formally, we say that there exists an isomorphism between $G_{1}$ and $G_{2}$, that is, a bijection between their vertex sets that preserves edges, for instance: $a \leftrightarrow x, b \leftrightarrow y, c \leftrightarrow z, d \leftrightarrow t$.

Focusing now on the local aspects of graphs, we say that two vertices are adjacent if they are connected by an edge. Thus, the degree of a vertex is the number of 


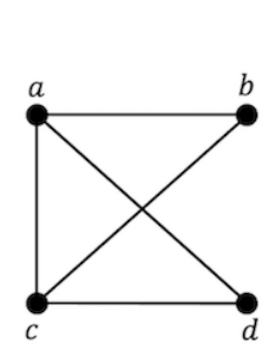

(a)

$$
\begin{array}{llll}
a & b & c & d
\end{array}
$$

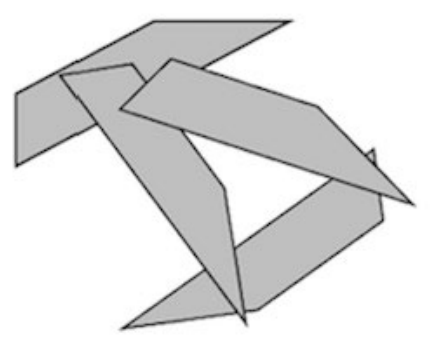

(c)

$$
G_{1}=(3,2,3,2)
$$

Figure 1. Some representations of graph $G_{1}$

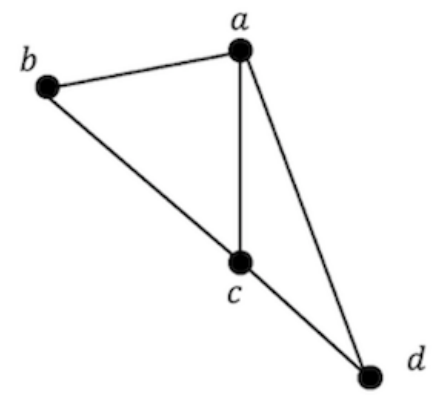

(a)

Figure 2. Pictorial representations of graph $G_{1}$

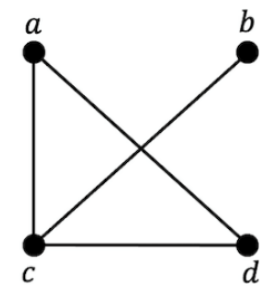

(a)

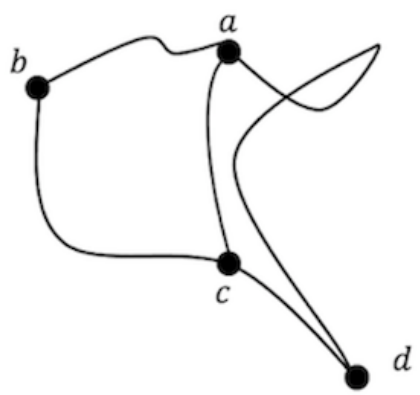

(b)

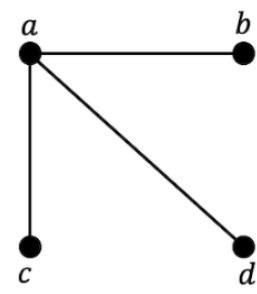

(b)

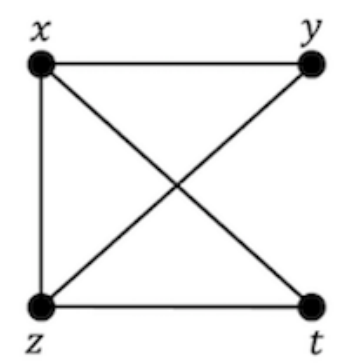

(c)

Figure 3. Some subgraphs of graph $G_{1}$

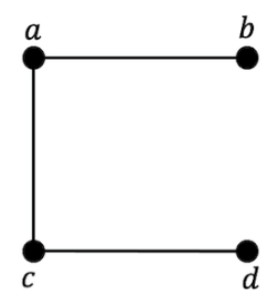

(c) vertices adjacent to it. For instance, in graph $G_{1}$, vertex $a$ has degree 3 and vertex $d$ has degree 2 . Also, a graph $G^{\prime}$ is said to be a subgraph of a graph $G$ (or $G^{\prime}$ is contained in $G$ ) if the vertices and edges of $G^{\prime}$ are contained in the vertices and edges of $G$, respectively. (Three different subgraphs of graph $G_{1}$ are shown in Figure 3).

Note that the examples of graphs presented so far are connected, that is, any pair of vertices can be joined by a sequence of edges of the graph. An example of a nonconnected graph is $G_{3}=(\{a, b, c, d, e\},\{a b, a c, b c, d e\})$, where, for example, the vertices $a$ and $e$ cannot be joined by any sequence of edges of $G_{3}$.

These notions enable us to define classic families of graphs: complete graphs, which are those graphs with any pair of vertices joined by an edge; cycles, which are connected graphs having every vertex of degree 2 ; and paths, which are connected graphs with two vertices of degree 1 and the rest of the vertices with degree 2. (In Figures 4(a), 4(b) and 4(c) a complete graph with 4 vertices, a cycle with 6 vertices and a path with 5 vertices are shown, respectively).

Another classical family is named trees, which are connected graphs that do not contain any cycle (Figure
5). The following properties are equivalent: (1) $G$ is a tree, (2) any two vertices of $G$ are connected by a unique path, (3) $G$ is connected, and its number of edges plus one is equal to its number of vertices.

One of the most common problems that teachers use to introduce graph theory to their students is the vertex coloring problem, probably because of its simple approach, which does not require any previous mathematical knowledge. Formally, a vertex coloring with $k$ colors of a graph $G$ is an assignment of an element of $\{1$, $2, \ldots, k\}$ (called set of colors) to each vertex of $G$, in such a way that two adjacent vertices have different colors. The minimum $k$ so that this is possible is called the chromatic number of $G$. It is easy to check that the chromatic number of any path is 2, and the chromatic number of any complete graph is equal to its number of vertices.

Another important problem in graph theory, which has been widely studied because of its multiple applications, is the study of the Eulerian character. We say that a graph is Eulerian if there exists a sequence of adjacent vertices that starts and finishes in the same vertex, and we can traverse the whole graph by following this sequence, going through every edge 


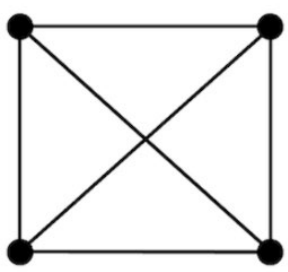

(a)

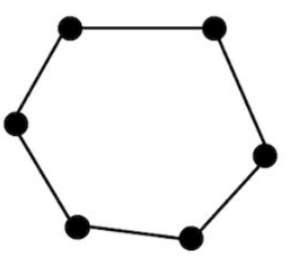

(b)

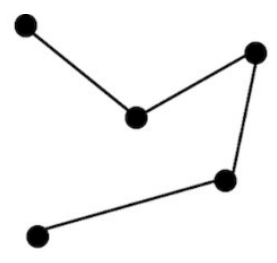

(c)

Figure 4. a. Example of complete graph; $\mathbf{b}$. Example of cycle; $\mathbf{c}$. Example of path.

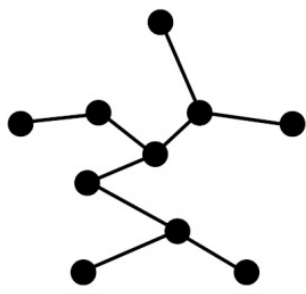

(a)

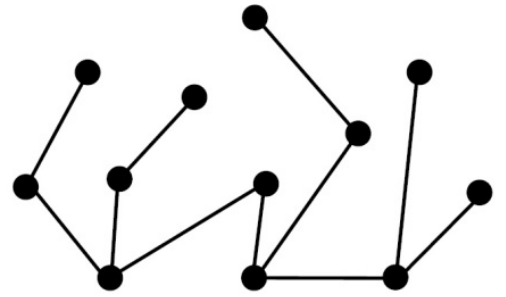

(b)

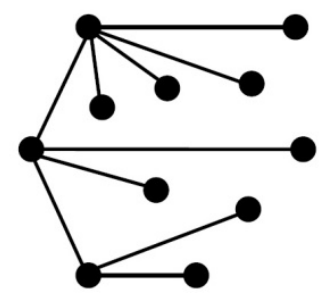

(c)

Figure 5. Examples of trees

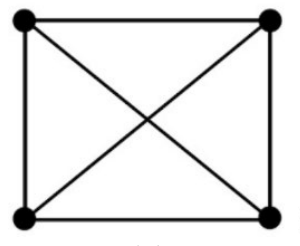

(a)

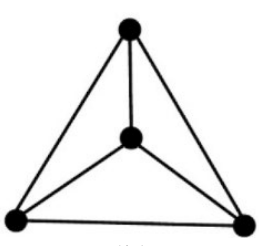

(b)

Figure 6. A representation of the complete graph with 4 vertices

exactly once. A well-known characterization of this property is that a graph is Eulerian if and only if every vertex has an even degree. Hence, complete graphs with an odd number of vertices and all cycles are examples of Eulerian graphs.

Finally, we say that a graph is planar if it has a pictorial representation without edge crossings. The complete graph with 4 vertices is planar because, although the representation in Figure 6(a) has an edge crossing, there exists a different one with no edge crossings, as Figure 6(b) shows. It is well-known that a planar graph cannot contain the complete graph with 5 vertices as a subgraph, and this is a necessary condition that could be useful to decide whether a graph is planar or not.

All the properties that we have presented can be divided into global and local properties, which will be necessary for our study. The chromatic number, planarity, Eulerianity, and connectivity are global properties, that is, they are associated with the whole graph; while the degree is a local property associated with each vertex. Observe that some global properties are defined in terms of local properties, for instance, connectivity, which requires that any pair of vertices of the graph be connected by a path. Similarly, Eulerianity is defined by means of a global structure (closed vertex sequence), and it is also characterized in local terms (an even degree of each vertex).

\section{METHODOLOGY}

We have developed a model for the learning of graph theory through a theoretical analysis, which is the starting point in the creation process of many educational models (Jaime \& Gutiérrez, 1990). The need for this type of analysis lies in its utility when designing data collection instruments for empirical studies. Indeed, when theoretical analyses are carried out, precisely the number of data collections is minimized, which is relevant due to the difficulties encountered by educational researchers when trying to access samples of a significant number of students.

Numerous frameworks explicitly include a theoretical analysis as an initial step in their research cycle, as is the case of the APOS theory (Arnon et al., 2014), whose theoretical analysis culminates in the socalled preliminary genetic decomposition. This is a hypothetical model of the mental structures and mechanisms that a student may need to build a specific mathematical concept: numerical sequence (Bajo, Gavilán-Izquierdo, \& Sánchez-Matamoros, 2019), linear transformation (Roa-Fuentes \& Oktaç, 2010), derivative (Borji, Alamolhodaei, \& Radmehr, 2018), vector space (Parraguez \& Oktaç, 2010), eigenvectors and eigenvalues (Salgado \& Trigueros, 2015); among others. In these works, the authors carry out their theoretical analyses based on one or more data sources: researchers' mathematical understanding of the concept, their experiences as teachers, prior research on students' 
thinking about the concept, historical perspectives on the development of the concept, and/or an analysis of text or instructional materials related to the concept (Arnon et al., 2014). In later phases of the research cycle, this theoretical model is experimentally tested and, depending on the results obtained, can be refined.

In the case of the van Hiele theory, it is also frequent to first design a characterization of the van Hiele levels with the same role as the preliminary genetic decompositions in APOS theory. For instance, LlorensFuster and Pérez-Carreras (1997) make an initial proposal of van Hiele level descriptors for the concept of local approximation mainly based on a review of literature. In the same spirit, our work provides an initial characterization of the van Hiele levels for graph theory that, in order to guarantee its accuracy, is based on the following sources:

1. Prior research on students' mathematical thinking. We set up a characterization of levels of reasoning in graph theory with the help of the literature review outlined above. Indeed, we have adapted the processes of geometric reasoning (Gutiérrez \& Jaime, 1998) to graph theory following an analogical reasoning procedure (Pólya, 1954), which is possible because of the similarities (Cañadas et al., 2008) between both fields of mathematics as we have described above. Thus, the descriptors of each process have been deduced from specific studies on the teaching and learning of graph theory.

2. Our mathematical understanding of the concept of graph as researchers in mathematics and didactics of mathematics. This study requires a multidisciplinary team able to deal with both didactical and mathematical concepts. Indeed, a deep knowledge of didactics of mathematics that only a researcher in this field can have is necessary to develop a learning model. Also, graphs have a series of peculiarities that cannot be directly deduced from geometry: the distinction between global and local properties, translations between representation systems, the concept of graph as a formal mathematical object, etc. All these aspects demand a deep understanding of graph theory that only experienced researchers in the field could handle.

3. Our experience as graph theory teachers. Two of the authors of this study have experience in teaching graph theory to engineering students. This has allowed us to design the descriptors of the van Hiele levels in graph theory not only from our literature review but also considering students' answers that we have observed throughout decades of teaching experience.

\section{RESULTS}

In this section, the four van Hiele levels for the learning of graph theory that we propose are provided. Each subsection is devoted to describing the evolution of each process of reasoning along the levels. We next specify, for each process of reasoning, its corresponding meaning in the context of the learning of graph theory.

- Recognition involves the identification of particular graphs, subgraphs, families of graphs, and both local and global properties, as well as the relations between properties and representation systems.

- Use of definitions comprises the handling of concepts to solve any task proposed in the context of graph theory, which includes the understanding of properties, steps of algorithms, combinatorial structures associated to graphs, etc.

- Formulation of definitions is the ability to describe and/or characterize notions of graph theory such as properties, families, etc.

- Classification is the process of organizing graphs into families according to properties, which may require some logical skills to understand the relationships that can appear between graph classes.

- Proof of statements in graph theory consists of proving classical theorems, equivalence of definitions, validity of algorithms, among other types of results.

\section{Recognition}

Level 1 students can recognize graphs by the visual appearance of the representations they know and perceive them as individual entities. Vertices and edges are the only elements of graphs that they can recognize because of their clear different appearance in any representation system. These students can recognize different representations for the same graph, even in different representation systems (provided that they are familiar to them), but only when there is a visual resemblance between those representations (see Figures $7(a), 7(b)$ and $7(\mathrm{c}))$. This implies a limitation of the variety of known representations that can generate difficulties when students try to identify a graph represented differently from what they are used to. For example, if we show Figure 7 to level 1 students who only know about pictorial representations of cycles without edge crossings, they most likely only recognize the 6-vertex cycle in Figures 7(a) and 7(b). 


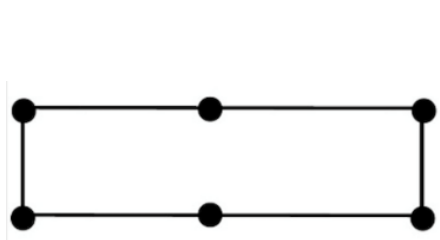

(a)

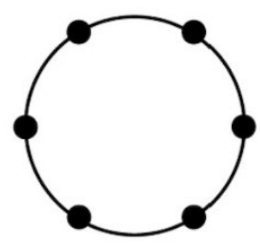

(b)

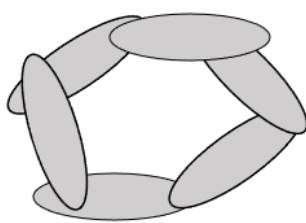

(c)

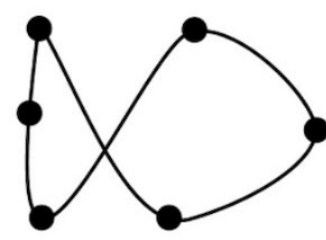

(d)

Figure 7. The 6-vertex cycle

As students are familiar with more representations for the same graph, they better perceive that what they have in common is the "way" in which their vertices are connected (this ability is explicit at the second level when they understand that this is precisely what characterizes a graph). Thus, level 1 students can identify graph families that are easy to characterize from their visual aspect, such as cycles and paths, whose tracings remind them of the locus of a curve, either closed in the case of cycles or open in the case of paths. However, they cannot recognize many trees since this family is more difficult to be characterized in visual terms because of the complexity of its definition. It will be at level 2 when all these families are explicitly recognized by their defining properties: connectivity, degree of vertices (in the case of paths and cycles), and acyclic character (in the case of trees).

Another important feature of students at level 1 is the partial recognition of global properties. The term "partial" refers to the fact that students, instead of assigning these properties to graphs, wrongly associate them with particular representations. For example, planarity is recognizable at this level, leading to "visually detecting" intersections among edges. When we ask students if a graph is planar, they first resort to a particular representation to make visual verifications, and then very diverse situations may arise. In the best scenario, the chosen representation will be sufficient to correctly determine that the graph is planar, but there are also other situations in which students may experience difficulties. Indeed, if the selected representation had edge crossings, they may not be looking for other representations since they usually confuse necessary conditions with sufficient conditions, thus deciding that the graph is not planar, which is not necessarily true. If they had found a representation with edge crossings and another without them, they could experience some confusion and be unable to decide.

When students have reached level 2, they can recognize local properties and subgraphs, which allows them to realize that a graph is exclusively characterized by the connections between its vertices, independently of its representation. Therefore, they can recognize some families of graphs by local properties, such as the degrees of the vertices: cycles (every vertex has degree 2), paths (every vertex has degree 2 except for two vertices which have degree 1$)$, and complete graphs (every vertex has degree equal to the number of vertices of the graph minus 1). They can also identify members of these families as subgraphs of other graphs, thus being able to analyze other local properties: cycles containing each vertex, paths between each pair of vertices, vertices of each complete subgraph, etc. This helps them identify more complex families, such as trees, which are locally characterized by the lack of cycles as subgraphs.

The analytical skills shown at this level allow students to identify families of graphs in any known representation system, thus translating from any system to another even when there are no visual similarities between the given representations. Nevertheless, they may encounter difficulties when understanding the limitations of each representation system, which requires a certain use of propositional logic that is achieved at the next level. For example, graphs represented as intersection of objects can always be transformed into a pictorial representation, but not vice versa, since this is only possible for the class of planar graphs.

There is a true recognition of global properties at level 2 since students no longer associate them with concrete representations but with a graph itself. Thus, they do not decide on specific representations with edge crossings but find a planar representation or argue why it does not exist. In addition, the ability to recognize local properties allows the student to identify global properties. Indeed, connectivity is not only visually perceived as "being of a single piece", as is usual at level 1 , but it is also understood as the property that each pair of vertices is connected by some path contained in the graph. However, some graph properties cannot be directly detected using their definitions when the number of vertices or edges is high. In these cases, it might be necessary to know relationships with other properties, which is difficult for the students at this level.

At level 3, students can recognize relationships between properties, making more efficient the process of recognition as they can understand and use simple logic rules such as $\mathrm{p} \rightarrow \mathrm{q}$ or $\urcorner \mathrm{q} \rightarrow \neg \mathrm{p}$. This feature is essential on many occasions when they strive to solve problems about graphs, as we have just discussed. For instance, students can decide directly that a graph is not planar whenever they find a complete graph on five vertices as a subgraph. In the same way, they can determine if a graph is Eulerian by checking the parity 
of the degrees of its vertices instead of searching for an appropriate sequence of edges. With these ideas in hand, students can identify properties in large graphs without applying their definitions.

Level 3 students have improved their understanding of the relationships between different representation systems thanks to the logical skills acquired at this level, thus overcoming the limitations they experienced at level 2. This shows a progress in the comprehension of the concept of graph that allows them to recognize this object in problems that have not necessarily been posed in a course in graph theory. For example, many engineering problems of incompatibilities among chemical substances can be solved using graph tools. Indeed, when several chemical compounds must be transported but some of them cannot share the same container, an incompatibility graph can be constructed considering the set of compounds as vertices and the incompatibilities as edges. Thus, the minimum number of containers can be obtained by computing the chromatic number of that incompatibility graph. However, due to the informal deduction character of this level, graphs are not yet perceived with the degree of formality of the next level.

Once students have reached level 4, they recognize graphs as formal mathematical objects, which implies a necessary extension of the three levels of recognition proposed by González and Gavilán-Izquierdo (2017). Thus, level 4 students can use graphs to prove results with the rigor that characterizes this level. For example, there exist multiple proofs of Kuratowski's theorem, whose statement may have been handled previously in the study of planarity. These proofs require a sufficiently flexible understanding of the concept of graph to handle it from a combinatorial, geometric, and topological perspective. Furthermore, certain problems in graph theory demand a sufficiently abstract perception to distinguish different structures that are associated to graphs. Indeed, in the context of metric graph theory, where a metric is defined in the graph, several sets can be constructed by means of some optimization problems on distances. Thus, to properly assimilate the differences between these sets, they cannot be regarded in specific graphs or even in classes of graphs, so they rather need to be understood through an abstract graph with generic properties, which requires a deep understanding of the concept of graph.

\section{Use of Definitions}

At level 1, students can assimilate definitions that do not require any knowledge of graph theory. For example, to handle the concept of coloring, it is enough to understand the task of assigning a color to each vertex of the given representation of a graph so that no edge has its vertices of the same color. Thus, level 1 students can easily perform the so-called greedy algorithm for coloring, which consists of assigning colors to the vertices in order: each vertex receives the first color which has not been assigned to any of the vertices adjacent to it. It is necessary to clarify that, although these activities have a local character (i.e., vertex to vertex), students do not need to be aware of local properties (characteristic of level 2). Indeed, they only have to visualize and differentiate the most elementary parts of a graph, vertices and edges, which have very different appearances in any representation system. Likewise, at this level, the definition of a specific graph, given by certain relationships among elements, can be used to construct a representation of that graph in a particular representation system that the student has previously known.

Level 2 students can use definitions with simple logical structure, that is, based on known properties of graphs, as long as these definitions only require basic logical skills such as the handling of conjunctions, disjunctions, and negations of logic statements. For example, they can use the definition of tree, since it is based on recognizable properties at this level: connectivity and absence of cycles. However, students may find difficult to use concepts such as chromatic number, which requires not only finding a suitable coloring but also proving that there is no other with fewer colors. Addressing this minimization problem may require some mastery of logic and relationships between properties, skills that are characteristic of the next level.

At level 3, students allow any definition since they recognize properties of graphs and know how to relate them to each other. They can therefore handle notions that previously implied a certain conflict, such as the concept of chromatic number. However, they may experience difficulties accepting several definitions for the same concept, for example, with the different characterizations for trees and Eulerian graphs. This problem is overcome at level $\mathbf{4}$ when students accept that the same object can have equivalent definitions. Thus, they can understand that a family of graphs can be characterized in different ways.

\section{Formulation of Definitions}

Level 1 students provide definitions as visual descriptions of graphs, making comparisons with objects of a geometric nature or even from everyday life, and using non-mathematical language. These students, who are strongly conditioned by the particular representations they know for each graph, may define cycles as "closed chains" or paths as "open sequences", "graphs with starting and final point", etc. The acquisition of level 2 allows formulating definitions as lists of mathematical properties, although in many cases they might contain redundancies and/or deficiencies. A possible definition of the five-vertex path 


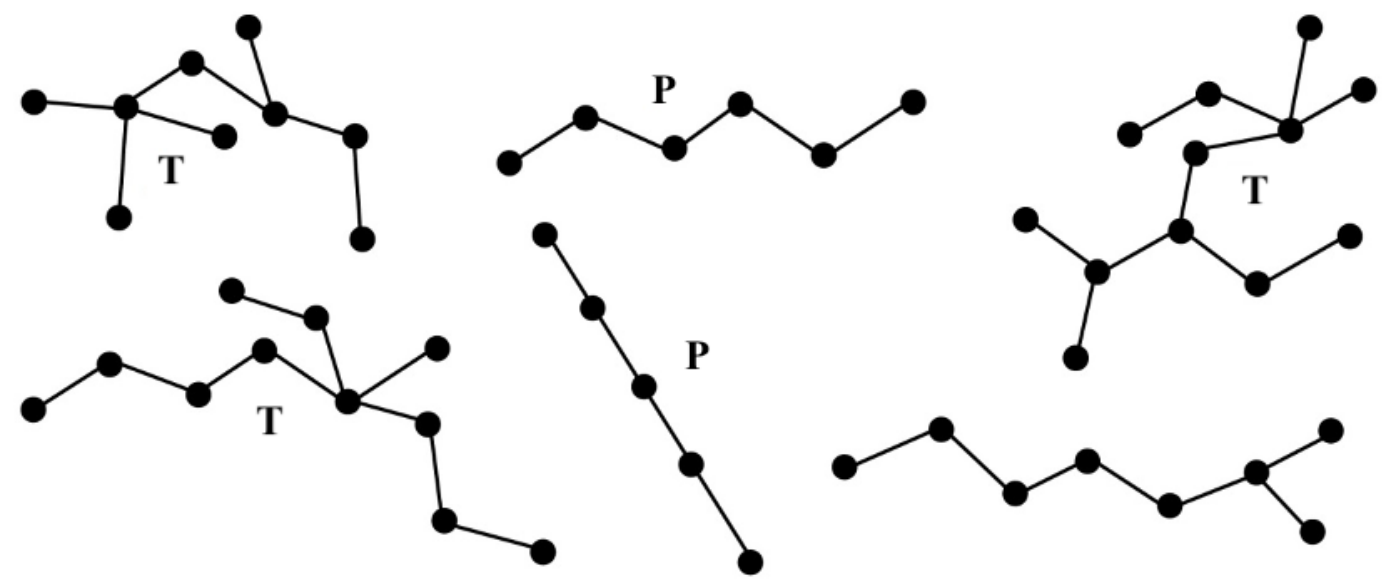

Figure 8. A possible classification made by a level 1 student

elaborated by students of this level could be: "a graph with five vertices, two of degree 1 and three of degree 2, and four edges". Thus, we observe that specifying the number of edges is redundant, and also that the definition should refer to the connectivity property.

At level 3, students write definitions as lists of necessary and sufficient conditions, striving to avoid redundancies and deficiencies. However, difficulties can arise when the construction of a definition requires formal deductions of several steps. For example, students at this level may be unable to elaborate the definition of tree as "a connected graph whose number of edges is one less than its number of vertices" themselves. Indeed, obtaining this definition requires a series of logical deductions, which is a feature of level 4. At this level, students can deduce any of the equivalent definitions for the same concept: tree, Eulerian graph, planar graph, etc. Thus, when students know a definition of some concept, they are able to formulate themselves an equivalent definition. For instance, students that have the definition of path as "connected graph having all its vertices of degree 2 except for two of degree 1 " can elaborate an alternative definition such as "the resulting graph from removing an edge from a cycle".

\section{Classification}

Students' progress through the classification process necessarily implies an improvement of their logical skills because of the variety of logical relationships that exist among graph families. For example, paths are included in the family of trees; the latter are disjoint with respect to cycles; trees have only two graphs in common with complete graphs (the paths on one and two vertices); etc.

Level 1 students perform partitional classifications based on visual recognition. Therefore, given two families such that one is included within the other, students perceive them as non-intersecting, as in the case of paths and trees. Thus, a possible classification made by a student at this level is shown in Figure 8, where letters $\mathrm{P}$ and $\mathrm{T}$ are used to label paths and trees respectively. Observe that paths have not been doubly labelled. In addition, one of the trees has not even been labelled. This student may justify the latter by saying that this graph "does not look like a path or a tree", reflecting the limitations of the purely visual recognition at this level.

Once students reach level 2, they can perform partitional classifications based on the mathematical properties of the graphs. Indeed, at this level, they can recognize global and local properties and use them to distinguish families of graphs, although they still cannot provide hierarchical classifications. Therefore, students at this level could perform the same classification that appears in Figure 8 but justifying their choices using properties: connectivity, absence of cycles, and degrees of the vertices. Besides, they would have assigned label $\mathrm{T}$ to the graph that had not been labeled by the level 1 student, since any tree is recognized at level 2.

At level 3, students can perform both partitional and hierarchical classifications, depending on the definition of the graph family that they are using. This is because they can already deduce some properties from others and therefore establish relationships between graph classes: inclusion, exclusion, and intersection. Thus, these students could provide the same classification for the graphs in Figure 8 as the level 2 students but doubly labeling paths with $\mathrm{P}$ and T. Furthermore, they could justify their choices by saying that "paths are particular cases of trees". At this level, students have completely developed the skill of classification in graph theory, and therefore this process cannot be used to discriminate between students at levels 3 and 4 .

\section{Proof}

Students at levels 1 and 2 check the veracity of a statement about graphs in one or more specific examples, thus believing that this is enough to prove it. For instance, when trying to prove that trees can be colored with two colors, they check this property in one or more examples. A difference between both levels is that level 1 students verify properties in particular 
representations instead of exploring other representations that may be necessary to verify those properties as level 2 students do. In fact, a level 1 student may check a property in two different representations of the same graph, thinking that they correspond to different graphs. Furthermore, many level 1 students use visual arguments such as "this is true because you can see it" or "because the shape of the graph looks like a circuit", instead of using examples. In addition to these limitations, they do not recognize local properties and many global properties, nor do they identify certain families that level 2 students do recognize and can use in their "proofs".

At level 3, students understand that particular examples are insufficient to prove a statement. Thus, they can produce informal proofs that require few logical steps and/or are obtained from the observation of examples. For instance, they can justify the statement "every tree can be colored with two colors" with some general ideas, but they cannot construct a formal proof, which requires mathematical induction and, therefore, greater knowledge of propositional logic. They can, at most, understand the steps of a formal proof once presented to them, but they cannot write it themselves. Only proofs with few steps could be elaborated by students at this level, such as the search for counterexamples, although they may need to be told in advance that they have to follow this method.

Finally, level 4 students can elaborate formal proofs with several logical steps, which is possible thanks to the recognition skills acquired at this level, which gives them a deep understanding of the concept of graph as a formal mathematical object. Thus, students at this level can prove a variety of statements on graphs (classical theorems and the validity of algorithms among others) by performing techniques widely used in graph theory: induction, proof by contradiction, proof by contraposition, etc.

\section{DISCUSSION}

The levels of reasoning that we have proposed for graphs follow the same structure as other proposals under the optics of the van Hiele model for a variety of mathematical concepts: plane geometric figures (Jaime \& Gutiérrez, 1990), plane isometries (Jaime, 1993), 3dimensional figures (Gutiérrez, 1992), local approximation (Llorens-Fuster \& Pérez-Carreras, 1997), convergence of sequences (Navarro \& Pérez-Carreras, 2006) or functions (Nisawa, 2018) among others. Indeed, we have first provided a level that is highly conditioned by visualization, followed by a second level of analytical nature. Our third level, which provides students with logical skills, is the necessary previous step to attaining the formal level, characterized by the use of graphs as abstract mathematical objects and the handling of formal proofs. Specifically, many descriptors of the levels of reasoning for graphs are analogous to the descriptors for geometric figures, provided that they refer to aspects that can be translated from geometry to graph theory. This is expectable regarding the similarities between both mathematical fields: the way to represent both mathematical objects and the fact that geometric invariants can be seen as particular cases of graph representation invariants, as discussed at the beginning of this work. However, those particularities of graphs that cannot be extrapolated from geometric figures have produced new descriptors that appear in our model. We next discuss the features of each level of reasoning in graph theory that we have presented. (See Table 1 for a summary of the main descriptors of each process at each level).

We have first provided a visual type level since it is well-known that visualization plays an important role in the learning of graph theory as a prior step for the acquisition of concepts (Milková, 2009; Schindler \& Joklitschke, 2015). In fact, Vergel et al. (2005) design tasks for graphs including the ideas of Piaget (1972) on the way that children construct their first spatial notions, which are topological (i.e., they perceive objects globally without paying attention to shape, size, angles, etc.). Thus, we have assumed that students at the first level can manipulate graphs globally through topological transformations, prior to the analytical perspective of the second level. Also, different authors assuming this idea have introduced graphs through visual definitions to students with no prior knowledge of graph theory. For example, Oller-Marcén and Muñoz-Escolano (2006) present graphs as points in the plane joined by lines.

Although the visual character of the recognition process at level 1 highly determines the remaining processes, the use of definitions at level 1 has a peculiarity for the geometric case that is worth mentioning. Indeed, students can deal with graph theory notions that, due to their simplicity, do not require any prior knowledge. In this sense, different studies show that primary and secondary school students can handle elementary properties of graphs (such as colorability, Eulerian character, or planarity) from their first contact with the subject (Cartier, 2008; Niman, 1975; OllerMarcén \& Muñoz-Escolano, 2006; Santoso, 2018; Wasserman, 2017). Specifically, Menéndez (1998) provides his students with a visual definition of an Eulerian graph such as "graphs that can be drawn without lifting the pencil from the paper, without going through a line twice and ending at the starting point". 
Table 1. Descriptors of each process of reasoning in graph theory at each level

\begin{tabular}{|c|c|c|c|c|}
\hline $\begin{array}{l}\text { Van Hiele levels } \\
\text { Processes }\end{array}$ & Level 1 & Level 2 & Level 3 & Level 4 \\
\hline \multirow[t]{3}{*}{ Recognition } & $\begin{array}{l}\text { Limitation to known } \\
\text { representations }\end{array}$ & $\begin{array}{l}\text { properties and } \\
\text { subgraphs }\end{array}$ & $\begin{array}{l}\text { Relationships between } \\
\text { properties }\end{array}$ & \multirow[t]{3}{*}{$\begin{array}{l}\text { Formal mathematical } \\
\text { objects }\end{array}$} \\
\hline & \multirow[t]{2}{*}{$\begin{array}{l}\text { Partial recognition of } \\
\text { global properties }\end{array}$} & $\begin{array}{l}\text { Independence of the } \\
\text { representation }\end{array}$ & \multirow[t]{2}{*}{$\begin{array}{l}\text { Relationships between } \\
\text { representation systems }\end{array}$} & \\
\hline & & $\begin{array}{l}\text { Translation between } \\
\text { representation systems }\end{array}$ & & \\
\hline Use of definitions & $\begin{array}{l}\text { Definitions that do not } \\
\text { require any knowledge } \\
\text { of graph theory }\end{array}$ & $\begin{array}{l}\text { Definitions with simple } \\
\text { logical structure }\end{array}$ & Any definition & $\begin{array}{l}\text { Accept equivalent } \\
\text { definitions }\end{array}$ \\
\hline \multirow{3}{*}{$\begin{array}{l}\text { Formulation of } \\
\text { definitions }\end{array}$} & Visual descriptions & \multirow{3}{*}{$\begin{array}{l}\text { List of mathematical } \\
\text { properties }\end{array}$} & \multirow{3}{*}{$\begin{array}{l}\text { Lists of necessary and } \\
\text { sufficient conditions }\end{array}$} & \multirow{3}{*}{$\begin{array}{l}\text { Formulate equivalent } \\
\text { definitions }\end{array}$} \\
\hline & $\begin{array}{l}\text { Comparisons with } \\
\text { everyday objects }\end{array}$ & & & \\
\hline & $\begin{array}{l}\text { Non-mathematical } \\
\text { Language }\end{array}$ & & & \\
\hline Classification & $\begin{array}{l}\text { Partitional, based on } \\
\text { visual recognition }\end{array}$ & $\begin{array}{l}\text { Partitional, based on } \\
\text { mathematical properties }\end{array}$ & Both partitional and hier & rarchical \\
\hline \multirow[t]{2}{*}{ Proof } & $\begin{array}{l}\text { Check in specific } \\
\text { examples of particular } \\
\text { representations of } \\
\text { graphs }\end{array}$ & $\begin{array}{l}\text { Check in specific } \\
\text { examples of graphs }\end{array}$ & \multirow[t]{2}{*}{ Informal proofs } & \multirow[t]{2}{*}{ Formal proofs } \\
\hline & Visual arguments & & & \\
\hline
\end{tabular}

In spite of the relevance of visualization in the learning of graph theory, we have highlighted in our results that level 1 students are strongly conditioned by the concrete representations they know for each graph. Using the terminology of Parzysz (1988), we can claim that students at level 1 only handle drawings, whereas level 2 students can also manage figures. Indeed, this author considers, in a geometrical context, the difference between a figure as an object characterized by mathematical properties, and a drawing as a particular plane representation of a figure (see also the papers of Laborde and Capponi (1994), and Marrades and Gutiérrez (2000)). Hence, these terms can be translated to graph theory by identifying graphs with figures and particular representations with drawings, thus following the spirit of our methodology in this work (i.e., the search for analogies between geometric figures and graphs). In the same line, Hershkowitz (1989) mentions the limitations of a purely visual judgment in the context of geometry, shown, for instance, by students highly conditioned by prototypical examples that try to assimilate a concept. Likewise, Hazzan and Hadar (2005) interpret visualization as a mechanism of reduction of the level of abstraction in graph theory that restricts students to a weak understanding of the concepts. In addition to these limitations, the absence of logical skills at this level, even for distinguishing necessary conditions to sufficient conditions, makes students to have difficulties when handling graph properties like planarity, which is expectable in the first van Hiele level for any mathematical object (Jaime \& Gutiérrez, 1998; Llorens-Fuster \& Pérez-Carreras, 1997; Navarro \& PérezCarreras, 2006; Nisawa, 2018). In order to progress in the learning of graph theory, students must overcome all these difficulties at the next level.

The achievement of the second level qualifies students for a local type of recognition that transcends the global perception of the preceding level. This agrees with the ideas of different authors claiming that the teaching of graph theory should go from the global to the local aspects. For instance, Gibson (2012) designs a sequence of tasks that initially present graphs as integral wholes and sequentially focus on their parts, thus making students pay attention to local concepts such as subgraphs or minimal paths (see also the work of Ferrarello (2017)). Hart and Martin (2018) also emphasize students' ability to detach from the irrelevant characteristics of graphs in order to give more importance to their combinatorial aspects. Hence, all these recognition skills of analytical nature must determine the development of the remaining processes, which are based on mathematical properties for the first time. Specifically, in the process of proof, level 2 students can use real examples of graphs instead of particular representations. This agrees with the perspective of Hazzan and Hadar (2005), whose main objective in the learning of graph theory is precisely the attainment of independence from the visual component. 
Level 3 students must overcome the difficulties they found at the previous level concerning logical skills since they can now understand and use simple logic rules. Such difficulties are detected by Cartier (2008) among her students when distinguishing between necessary and sufficient conditions of Eulerianity. Likewise, Vergel et al. (2005) observe difficulties when students strive to find a precise criterion of semieulerianity, even if they show an analytical understanding of this property. This supports our idea that recognizing relationships between properties, the key of level 3 , is more complex than recognizing isolated properties (level 2). In fact, the recognition skills of level 2 are integrated at level 3 with the help of logic and abstraction.

Recognizing relations between properties allows level 3 students to improve their mastery in other abilities like handling graph concepts (use and formulation of definitions) more rigorously or providing logical classifications. This is due to the fact that they are able to understand and use not only simple logic rules but any logic relationship: existential and universal quantifiers, equivalences, minimums, maximums, etc. Their abstraction skills also allow them to realize that particular examples are insufficient to prove statements, thus giving general arguments instead of describing specific examples. Another feasible activity at this level consists of developing conjectures employing logical arguments without any teacher guidance. Ferrarello and Mammana (2018) propose this activity for students with certain competence in reasoning (specifically, for high school students), in line with our vision of level 3 as an intermediate step necessary to understand the formal aspects acquired at the next level.

Level 4 reflects the degree of formality necessary to deal with certain problems posed in advanced courses in graph theory, such as university-level subjects (Milková, 2009; Tabchi, 2018). In Spanish universities, graphs are mainly taught in degrees in mathematics and engineering (González et al., 2019). In the former case, mathematics students have to reach the highest degree of understanding of the graph concept as an abstract mathematical object. This fact leads them to write formal proofs, among other essential aspects that occur at level 4. Concerning engineering degrees, especially in computer science, students frequently have to deal with algorithms (Do et al., 2018; Medová et al., 2019; Tabchi et al., 2019), so they should not be limited to merely applying them. Indeed, they should achieve a sufficiently deep understanding of graph theory to prove the validity of algorithms at a theoretical level for future practical implementation. Hence, acquiring all these features of level 4 implies a reorganization of the previous level's skills since constructing a proof consists precisely of linking different relations among properties, which were first identified at level 3.

\section{CONCLUSION}

In this work, we have characterized levels of reasoning in graph theory by extending the van Hiele model to this field of mathematics. In order to do this, we have implemented a theoretical analysis based on three data sources: a review of the literature on the teaching and learning of graph theory and the van Hiele model, our mathematical understanding of the concept of graph as researchers in mathematics and didactics of mathematics, and our experience as graph theory teachers. We have thus obtained four different levels of reasoning of graph theory students whose descriptors have been organized utilizing the processes of reasoning: recognition, use and formulation of definitions, classification, and proof. These levels follow the same spirit as levels proposed for other particularizations of the van Hiele model: visualization, analysis, informal deduction, and formal deduction.

Our study addresses a research problem that is relevant in mathematics education: to extend a theoretical framework (the van Hiele model) to learning a mathematical object (graph) that had never been studied from this approach. The characterization of students' thinking that we have obtained is necessary to design data collection instruments for empirical studies. Furthermore, we have developed a methodology with the aid of the processes of reasoning that can be useful for future research that looks for indicators of van Hiele levels of reasoning for other mathematical concepts.

Different lines for future research may be developed from our work. On the one hand, it could be interesting to address theoretical studies on issues that we have not considered in this paper. For instance, the structural properties of the van Hiele levels in graph theory should be checked, and a comparison with the van Hiele levels of geometric thinking, which have guided our results, might be accomplished. Also, the reasoning of professional mathematicians could be considered in order to provide a fifth level of thinking in graph theory, thus extending our model for students. Indeed, many graph theory problems only arise in a research context, for instance when graphs must be regarded as particular cases of other combinatorial structures: hypergraphs, multigraphs, Euclidean networks, etc. On the other hand, it is necessary to launch empirical studies to evaluate students' levels of reasoning in graph theory, thus allowing us to refine the theoretical characterization that we have presented here. Indeed, our approach can serve as a guide for designing efficient assessment instruments for each process of reasoning in graph theory since we have detailed with examples the descriptors of each level. Once we have designed those instruments, we can search for samples of students having some knowledge on graphs (for instance those of mathematics or engineering degrees), and then assess their levels of reasoning. Thus, we can compare the 
experimental results with the theoretical characterization of this work, and subsequently reconsider (if necessary) some of the descriptors provided here. Both lines can contribute to the creation of task sequences according to the features of each level so that teachers may use them to help their students' progress in the learning of graph theory.

Author contributions: All authors have sufficiently contributed to the study, and agreed with the results and conclusions.

Funding: The first, second and third authors were partially supported by the "VI Plan Propio de Investigación y Transferencia" of the Universidad de Sevilla (Spain) and by the Research Group in Mathematics Education FQM-226 of the Junta de Andalucía (Spain). The fourth author was partially supported by the Research Group Supercomputation-Algorithms TIC-146 of the Junta de Andalucía (Spain).

Declaration of interest: No conflict of interest is declared by authors.

\section{REFERENCES}

Aires, A. P., Campos, H., \& Poças, R. (2015). Raciocínio geométrico versus definição de conceitos: a definição de quadrado com alunos de $6^{\circ}$ ano de escolaridade [Geometric reasoning vs definition of concepts: The definition of square with 6 th grade students]. Revista Latinoamericana de Investigación en Matemática Educativa, 18(2), 151-176. https:/ / doi.org/10.12802/relime.13.1821

Alsina, C. (2011). Mapas del metro y redes neuronales. La teoría de grafos [Subway maps and neural networks. Graph theory]. RBA.

Armah, R. B., \& Kissi, P. S. (2019). Use of the van Hiele theory in investigating teaching strategies used by college of education geometry tutors. Eurasia Journal of Mathematics, Science and Technology Education, 15(4), em1694. https://doi.org/10.29333 / ejmste/103562

Arnon, I., Cottrill, J., Dubinsky, E., Oktaç, A., Fuentes, S. R., Trigueros, M., \& Weller, K. (2014). APOS theory: A framework for research and curriculum development in mathematics education. Springer. https:/ / doi.org/ 10.1007/978-1-4614-7966-6

Bajo, J. M., Gavilán-Izquierdo, J. M., \& SánchezMatamoros, G. (2019). Caracterización del esquema de sucesión numérica en estudiantes de Educación Secundaria Obligatoria [Characterization of the numeric sequence schema among Compulsory Secondary Education students]. Enseñanza de las ciencias, 37(3), 149-167. https://doi.org/10.5565/ rev/ensciencias.2673

Beineke, L. W., \& Wilson, R. J. (1997). Graph connections: Relationships between graph theory and other areas of mathematics. Oxford University Press.

Biggs, N. L. (2003). Discrete mathematics (2nd ed.). Oxford University Press.

Bleeker, C., Stols, G., \& Van Putten, S. (2013). The relationship between teachers' instructional practices and their learners' level of geometrical thinking. Perspectives in Education, 31(3), 66-78.

Borji, V., Alamolhodaei, H., \& Radmehr, F. (2018). Application of the APOS-ACE theory to improve students' graphical understanding of derivative. Eurasia Journal of Mathematics, Science and Technology Education, 14(7), 2947-2967. https://doi.org/10.29333/ ejmste/91451

Brito, L. P., Almeida, L. S., \& Osório, A. J. M. (2020). Reasoning abilities and learning math: A Möbius strip? International Electronic Journal of Mathematics Education, 15(2), em0565. https://doi.org/10.29333 /iejme/ 6259

Bruckler, F. M., \& Stilinović, V. (2008). Graph theory as a method of improving chemistry and mathematics curricula. In B. Sriraman, C. Michelsen, A. Beckmann, \& V. Freiman (Eds.), Proceedings of the 2nd International Symposium on Mathematics and its Connections to the Arts and Sciences (pp. 117-126). Print \& Sign.

Burger, W., \& Shaughnessy, J. (1986). Characterizing the van Hiele levels of development in geometry. Journal for Research in Mathematics Education, 17(1), 31-48. https:/ / doi.org/10.2307/749317

Cañadas, M. C., Deulofeu, J., Figueiras, L., Reid, D. A., \& Yevdokimov, O. (2008). Perspectivas teóricas en el proceso de elaboración de conjeturas e implicaciones para la práctica: Tipos y pasos [Theoretical perspectives in the process of producing conjectures and implications for practice: Types and steps]. Enseñanza de las Ciencias, 26(3), 431-444. https://doi.org/10.5565/rev/ ensciencias. 3753

Cartier, L. (2008). Le graphe comme outil pour enseigner la preuve et la modélisation [Graphs as tools for teaching proof and modeling]. [Doctoral thesis, Institut Fourier, Grenoble, France]. HAL archivesouvertes.fr. https://tel.archives-ouvertes.fr/tel00416598v1

Chaphalkar, R., \& Wu, K. (2020). Students' reasoning about variability in graphs during an introductory statistics course. International Electronic Journal of Mathematics Education, 15(2), em0580. https:// doi.org/10.29333/iejme/7602

Chinn, P.Z. (1993). Discovery-method teaching in graph theory. Annals of Discrete Mathematics, 55, 375-384. https:/ / doi.org/10.1016/S0167-5060(08)70402-3

Costa, G., D'Ambrosio, C., \& Martello, S. (2014). Graphsj 3: A modern didactic application for graph algorithms. Journal of Computer Science, 10(7), 11151119. https: / / doi.org/10.3844/jcssp.2014.1115.1119

Derrible, S., \& Kennedy, C. (2011). Applications of graph theory and network science to transit network 
design. Transport reviews, 31(4), 495-519. https:/ / doi.org/10.1080/01441647.2010.543709

Díaz-Levicoy, D. (2010). Determinación de niveles Van Hiele en alumnos de primer año medio sobre la transformación isométrica de simetría [Determination of Van Hiele levels in first year middle school students on the isometric transformation of symmetry]. Revista investigaciones en educación, 10(2), 65-87.

Do, N. V., Nguyen, H. D., \& Mai, T. T. (2018). Intelligent educational software in discrete mathematics and graph theory. Frontiers in Artificial Intelligence and Applications, 303, 925-938.

Ferrarello, D. (2017). Graphs in primary school: Playing with technology. In G. Aldon, F. Aldon, L. Bazzini, \& U. Gellert (Eds.), Mathematics and Technology. Advances in Mathematics Education (pp. 143-169). Springer. $\quad$ https://doi.org/10.1007/978-3-31951380-5_8

Ferrarello, D., \& Mammana, M. F. (2018). Graph theory in primary, middle, and high school. In E. W. Hart \& J. Sandefur (Eds.), Teaching and learning discrete mathematics worldwide: Curriculum and research. ICME-13 Monographs (pp. 183-200). Springer. https:/ / doi.org/10.1007/978-3-319-70308-4_12

Gavilán-Izquierdo, J. M., \& González, A. (2016). Investigación sobre el concepto de grafo a través del modelo de Van Hiele [Research on the concept of graph through the Van Hiele model]. In J. A. Macías, A. Jiménez, J. L. González, M. T. Sánchez, P. Hernández, C. Fernández, F. J. Ruiz, T. Fernández, \& A. Berciano (Eds.), Investigación en Educación Matemática XX (p. 597). SEIEM.

Geschke, A., Kortenkamp, U., Lutz-Westphal, B., \& Materlik, D. (2005). Visage - visualization of algorithms in discrete mathematics. ZDM Mathematics Education, 37(5), 395-401. https:// doi.org/10.1007/s11858-005-0027-z

Gibson, J. P. (2012). Teaching graph algorithms to children of all ages. Proceedings of the 17th Annual ACM Conference on Innovation and Technology in Computer Science Education (pp. 34-39). ACM. https:/ / doi.org/10.1145/2325296.2325308

González, A., \& Gavilán-Izquierdo, J. M. (2017). Analizando el reconocimiento de grafos a través del modelo de Van Hiele [Analyzing the recognition of graphs through the Van Hiele model]. In Federación Española de Sociedades de Profesores de Matemáticas (Ed.), VIII Congreso Iberoamericano de Educación Matemática. Libro de actas (pp. 286-293). FESPM.

González, A., Muñoz-Escolano, J. M., \& Oller-Marcén, A. M. (2019). Presencia de la teoría de grafos en la enseñanza de grado en España [Presence of graph theory in undergraduate teaching in Spain]. In J. M.
Marbán, M. Arce, A. Maroto, J. M. MuñozEscolano, \& Á. Alsina (Eds.), Investigación en Educación Matemática XXIII (p. 622). SEIEM.

Gutiérrez, A. (1992). Exploring the links between van Hiele levels and 3-dimensional geometry. Structural Topology, 18, 31-48.

Gutiérrez, A., \& Jaime, A. (1998). On the assessment of the van Hiele levels of reasoning. Focus on Learning problems in Mathematics, 20(2/3), 27-46.

Hart, E. (2008). Vertex-edge graphs: An essential topic in high school geometry. The Mathematics Teacher, 102(3), 178-185. https://doi.org/10.5951/MT.102. 3.0178

Hart, E. W., \& Martin, W. G. (2018). Discrete mathematics is essential mathematics in a 21st century school curriculum. In E. W. Hart \& J. Sandefur (Eds.), Teaching and learning discrete mathematics worldwide: Curriculum and research. ICME-13 Monographs (pp. 3-19). Springer. https:// doi.org/10.1007/978-3-319-70308-4_1

Hart, E. W., Kenney, M. J., DeBellis, V. A., \& Rosenstein, J. G. (2008). Navigating through discrete mathematics in grades 6 to 12. National Council of Teachers of Mathematics.

Hart, E.W., \& Sandefur, J. (Eds.) (2018). Teaching and learning discrete mathematics worldwide: Curriculum and research. Springer. https://doi.org/10.1007/ 978-3-319-70308-4

Hazzan, O., \& Hadar, I. (2005). Reducing abstraction when learning graph theory. Journal of Computers in Mathematics and Science Teaching, 24(3), 255-272. http://citeseerx.ist.psu.edu/viewdoc/download? doi=10.1.1.96.5275\&rep=rep1\&type $=$ pdf

Hershkowitz, R. (1989). Visualization in geometry - Two sides of the coin. Focus on Learning Problems in Mathematics, 11(1-2), 61-76.

Hoffer, A. (1988). Geometry and visual thinking. In T. R. Post (Ed.), Teaching mathematics in grades K-8: Research based methods (pp. 233-261). Allyn \& Bacon.

Hokor, E. K. (2020). Pre-service teachers' probabilistic reasoning in constructivist classroom. Pedagogical Research, 5(2), em0053. https://doi.org/10.29333/ pr/7838

Jaime, A. (1993). Aportaciones a la interpretación y aplicación del modelo de Van Hiele: la enseñanza de las isometrías del plano. La evaluación del nivel de razonamiento [Contributions to the interpretation and application of the Van Hiele model: The teaching of plane isometries. The evaluation of the level of reasoning] [Doctoral dissertation, Universitat de València].

Jaime, A., \& Gutiérrez, A. (1990). Una propuesta de fundamentación para la enseñanza de la geometría: El modelo de van Hiele [A proposal for the foundation for the teaching of geometry: The van 
Hiele model]. In S. Llinares \& V. M. Sánchez (Eds.), Teoría y práctica en educación matemática (pp. 295384). Alfar.

Kasyanov, V. N. (2001). Support tools for graphs in computer science education. In T. Okamoto, $\mathrm{R}$. Hartley, T. Kinshuk, \& J. P. Klus (Eds.), Proceedings of the IEEE International Conference on Advanced Learning Technologies (pp. 307-308). IEEE Computer Society.

https:/ / doi.org/10.1109/ICALT.2001.943930

Kolman, P., Zach, P., \& Holoubek, J. (2013). The development of e-learning applications solving problems from graph theory. Acta Universitatis Agriculturae et Silviculturae Mendelianae Brunensis, 61(7), 2311-2316. https://doi.org/10.11118/actaun 201361072311

Laborde, C., \& Capponi, B. (1994). Cabri-Géomètre constituant d'un milieu pour l'apprentissage de la notion de figure géométrique [Cabri-Géomètre constituting a medium for learning the concept of geometric figure]. Recherches en Didactique des Mathématiques, 14(1/2), 165-210.

Llorens-Fuster, J. L., \& Pérez-Carreras, P. (1997). An extension of van Hiele's model to the study of local approximation. International Journal of Mathematical Education in Science and Technology, 28(5), 713-726. https:/ / doi.org/10.1080/0020739970280508

Marrades, R., \& Gutiérrez, Á. (2000). Proofs produced by secondary school students learning geometry in a dynamic computer environment. Educational Studies in Mathematics, 44(1/2), 87-125. https:/ / doi.org/10.1023/A:1012785106627

Mayberry, J. (1983). The van Hiele levels of geometric thought in undergraduate preservice teachers. Journal for research in mathematics education, 14(1), 58-69. https:/ / doi.org/10.2307/748797

Medová, J., Páleníková, K., Rybanský, L'., \& Naštická, Z. (2019). Undergraduate students' solutions of modeling problems in algorithmic graph theory. Mathematics, 7(7), 572. https://doi.org/10.3390/ math7070572

Menéndez, A. (1998). Una breve introducción a la teoría de grafos [A brief introduction to graph theory]. Revista SUMA, 28, 11-26. https://redined.mecd. gob.es/xmlui/handle/11162/13526

Milková, E. (2009). Constructing knowledge in graph theory and combinatorial optimization. WSEAS Transactions on Mathematics, 8(8), 424-434.

Milková, E. (2014). Puzzles as excellent tool supporting graph problems understanding. Procedia-Social and Behavioral Sciences 131, 177-181. https://doi.org/ 10.1016/j.sbspro.2014.04.100

Navarro, M. A., \& Pérez-Carreras, P. (2006). Constructing a concept image of convergence of sequences in the van Hiele framework. CBMS Issues in Mathematics Education, 13, 61-98. https:/ / doi.org /10.1090/cbmath/013

Niman, J. (1975). Graph theory in the elementary school. Educational Studies in Mathematics, 6(3), 351-373. https:/ / doi.org/10.1007/BF01793617

Nisawa, Y. (2018). Applying van Hiele's levels to basic research on the difficulty factors behind understanding functions. International Electronic Journal of Mathematics Education, 13(2), 61-65. https:/ / doi.org/10.12973/iejme/2696

Oller-Marcén, A., \& Muñoz-Escolano, J. M. (2006). Euler jugando al dominó [Euler playing domino]. Revista SUMA, 53, 39-49.

Parraguez, M., \& Oktaç, A. (2010). Construction of the vector space concept from the viewpoint of APOS theory. Linear Algebra and its Applications, 432(8), 2112-2124.

https:/ / doi.org/10.1016/j.laa.2009.06.034

Parzysz, B. (1988). "Knowing" vs "seeing". Problems of the plane representation of space geometry figures. Educational Studies in Mathematics, 19(1), 79-92. https:/ / doi.org/10.1007/BF00428386

Pegg, J., Gutiérrez, A., \& Huerta, P. (1998). Assessing reasoning abilities in geometry. In C. Mammana \& V. Villani (Eds.), Perspectives on the teaching of geometry for the 21st century (pp. 275-295). Kluwer.

Piaget, J. (1972). Psicología y epistemología [Psychology and epistemology]. Emecé Editores.

Piaget, J., \& Inhelder, B. (1956). The child's conception of space. The Humanities Press.

Pólya, G. (1954). Mathematics and plausible reasoning, Volume 1: Induction and analogy in mathematics. Princeton University Press. https://doi.org/ 10.1515/9780691218304

Roa-Fuentes, S., \& Oktaç, A. (2010). Construcción de una descomposición genética: Análisis teórico del concepto transformación lineal [Constructing a genetic decomposition: Theoretical analysis of the linear transformation concept]. Revista Latinoamericana de Investigación en Matemática Educativa, 13(1), 89-112. http:/ / www.scielo.org.mx /pdf/relime/v13n1/v13n1a5.pdf

Rosenstein, J. G. (2018). The absence of discrete mathematics in primary and secondary education in the United States... and why that is counterproductive. In E. W. Hart \& J. Sandefur (Eds.), Teaching and learning discrete mathematics worldwide: Curriculum and research. ICME-13 Monographs (pp. 21-40). Springer. https:// doi.org/ 10.1007/978-3-319-70308-4_2

Salgado, H., \& Trigueros, M. (2015). Teaching eigenvalues and eigenvectors using models and APOS Theory. The Journal of Mathematical Behavior, 39, 100-120. https://doi.org/10.1016/j.jmathb. 2015.06.005 
Santoso, E. B. (2018). Mathematics classroom activities based on some topics in graph theory to develop critical thinking of primary and secondary school students. International Journal of Indonesian Education and Teaching, 2(2), 154-160. https: / / doi.org/10.24071/ijiet.2018.020207

Schindler, M., \& Joklitschke, J. (2015). Designing tasks for mathematically talented students. In K. Krainer \& N. Vondrová (Eds.), Proceedings of the Ninth Congress of the European Society for Research in Mathematics Education (CERME 9) (pp. 1066-1072). Charles University. https://hal.archivesouvertes.fr/hal-01287313/document

Smithers, D. B. (2005). Graph theory for the secondary school classroom [Master Thesis, East Tennessee State University]. dc.etsu.edu/etd/1015

Tabchi, T. (2018). University teachers-researchers' practices: The case of teaching discrete mathematics. In V. Durand-Guerrier, R. Hochmuth, S. Goodchild, \& N. M. Hogstad (Eds.), Proceedings of the second conference of the International Network for Didactic Research in University Mathematics (INDRUM 2018) (pp. 432-441). University of Agder and INDRUM. https://hal. archives-ouvertes.fr/hal-01849936/document

Tabchi, T., Sabra, H., \& Ouvrier-Buffet, C. (2019). Resources for teaching graph theory for engineers - issue of connectivity. In S. Rezat, L. Fan, M. Hattermann, J. Schumacher, \& H. Wuschke, (Eds.), Proceedings of the Third International Conference on
Mathematics Textbook Research and Development (pp. 323-328). Universitätsbibliothek Paderborn.

Toscano, L., Stella, S., \& Milotti, E. (2015). Using graph theory for automated electric circuit solving. European Journal of Physics, 36(3), 1-12. https: / / doi.org/10.1088/0143-0807/36/3/035015

Usiskin, Z. (1982). Van Hiele levels and achievement in secondary school geometry. CDASSG Project.

Van Hiele, P. M. (1986). Structure and insight. A theory of mathematics education. Academic Press.

Vergel, C., Molina, B., \& Echeverry, A. (2005). Grafos en la educación básica [Graphs in basic education]. Revista EMA, 10(2-3), 440-451. http://funes. uniandes.edu.co/1507/

Vidermanová, K., \& Melušová, J. (2011). Teaching graph theory with Cinderella and Visage: An undergraduate case. In D. Vallo, O. Sedivý, \& K. Vidermanová (Eds.), New Trends in Mathematics Education: DGS in Education (pp. 79-85). Constantine the Philosopher University.

Wasserman, N. H. (2017). Math madness: Coloring, reasoning, and celebrating. Teaching Children Mathematics, 23(8), 468-475. https://doi.org/ 10.5951/teacchilmath.23.8.0468

Yao, X., \& Elia, J. (2021). Connections between empirical and structural reasoning in technology-aided generalization activities. International Electronic Journal of Mathematics Education, 16(2), em0628. https://doi.org/10.29333/iejme/9770

\section{http://www.ejmste.com}

